\title{
Pedagogia crítica e Direitos Humanos: fundamentos para uma proposta pedagógico-crítica em Direitos Humanos ${ }^{1}$
}

\author{
Maria Elizete Guimarães Carvalho* \\ Carlos Alberto Vilar Estêvão***
}

\section{Resumo}

Este artigo reflete sobre a necessidade de encontrar uma teoria pedagógica que ofereça sustentação à ação educativa em Direitos Humanos, apresentando uma proposta pedagógico-crítica alicerçada nos pressupostos da teoria e da pedagogia críticas, privilegiando a pedagogia freireana, numa perspectiva atualizada para os Direitos Humanos. Nesse sentido, o trabalho tem o propósito de discutir um fundamento teórico-crítico para a Educação em Direitos Humanos, buscando novas formas de investigação e de análise para sua compreensão, apropriando-se de conceitos críticos como conscientização, autonomia, diálogo e emancipação. Finalmente, considera que uma prática pedagógica crítica em Direitos Humanos contribui para a leitura do mundo do excluído, para sua inclusão na sociedade e para a compreensão de que é possivel desconstruir relações e práticas sociais injustas. Palavras-chave: Teoria crítica. Pedagogia freireana. Proposta pedagógica em direitos humanos. Fundamentos críticos.

\section{Introdução}

Iniciamos este trabalho lembrando as dificuldades encontradas para trabalhar com Direitos Humanos - DH, tanto na Universidade como nas instituições escolares, e principalmente nas salas de Educação de Jovens e Adultos - EJA. São limites e fragilidades que se configuram como pouca consistência teórica para fundamentar ou esclarecer as próprias questões teóricas como também a prática pedagógica.

Tais questões refletem-se na indefinição de uma teoria pedagógica que ofereça sustentação a ação educativa, desconhecimento e/ou rejeição de professores e

1 Trabalho realizado para conclusão de Pós-Doutoramento em Ciências da Educação, especialidade em Política Educativa, Universidade do Minho/Braga/PT.

* Doutora em Educação. Professora da Universidade Federal da Paraíba. Bolsista da CAPES - Proc. ${ }^{\circ}$ 9549/11-0. mecarvalho23@yahoo.com.br.

** Doutor em Organização e Administração Escolar. Professor Colaborador. Departamento de Ciências Sociais da Educação, Instituto de Educação. Coordenador do Núcleo de Educação para os Direitos Humanos, Universidade do Minho/PT. cestevao@ie.uminho.pt. 
professoras, alunos e alunas às temáticas sugeridas/discutidas em círculos de debates, seminários e oficinas tanto no exercício da docência como no desenvolvimento de projetos de extensão e pesquisa. Os Direitos Humanos são muitas vezes entendidos, principalmente pelas "vítimas", como "aquilo que não serve para nada", desnecessários para suas vidas e não como conhecimentos básicos para todos os seres humanos. Nesse contexto de desconhecimento e incompreensão, sentimos então necessidade de uma abordagem teórico-pedagógica que, articulada a essa área do conhecimento, possa fortalecer os saberes e as práticas educativas dos professores e das professoras que optaram pelo trabalho em e para os Direitos Humanos.

Queremos esclarecer que esse sentimento ou percepção de carência teórica para alicerçar a prática educativa em Direitos Humanos não é um sentimento isolado, encontrando-se manifesto em autores como, por exemplo, Magendzo (2012), que na carta de apresentação de seu artigo Pedagogía crítica y educación en derechos humanos enfatiza as sérias carências na pedagogia que deveria orientar a tarefa educativa em Direitos Humanos.

Nesse sentido, procuramos caminhar na linha deste autor, buscando referentes teóricos para a prática educativa em Direitos Humanos, para que nosso trabalho possa ser feito de forma consciente e segura. A perspectiva de transformar-se em professores e professoras que trabalham em e para os Direitos Humanos, comprometidos com a promoção da justiça social e com o respeito à dignidade humana, implica saberes e conhecimentos novos e transformação, conceitos complexos que estão em consonância com as transformações sociais e necessidades criadas e aprofundadas no final do século XX e início do século XXI, o que demanda, entre outros aspectos, a sustentação teórica para a prática pedagógica.

Em face dessa realidade, afirmamos, apesar da disposição inicial e do reconhecimento da necessidade explicitada, que temos mais dúvidas que certezas, mais perguntas que respostas, muitas expectativas e também pedras para retirar do meio do caminho. Nessa trajetória, pressupomos limites e dificuldades, tendo em vista a necessidade de repensar, de colocar em discussão conhecimentos e certezas estabelecidas.

Ora, Freire (1994) anunciava, faz algum tempo, a incerteza como marca da pósmodernidade. "Uma das exigências da pós-modernidade progressista é não estarmos demasiado certos de nossas convicções, ao contrário do exagero de certezas da modernidade". (FREIRE, 1994, p. 19), fazendo sentido, portanto, nossas dúvidas e incertezas nesse momento.

Na perspectiva de encontrar um fundamento teórico-pedagógico para a Educação em Direitos Humanos, ocorreu nosso encontro com a Teoria e com a Pedagogia Crítica. Esse encontro foi providencial, pois percebemos que premissas fundamentais para a Teoria e para a Pedagogia Crítica, também o eram para os Direitos Humanos. 
Compreendemos que a Pedagogia Crítica poderia oferecer algumas respostas aos nossos questionamentos, esclarecer dúvidas, contribuir para a retirada de pedras no meio do caminho, porque, tanto a Pedagogia Crítica como os Direitos Humanos propõem a erradicação do sofrimento humano, principalmente como tarefa educacional se todos estiverem empenhados, pela razão do sofrimento ser "um fenômeno construído pela própria espécie e que não tem porque existir". (KINCHELOE, 2008, p. 40).

À luz dessas reflexões iniciais, ganha sentido a necessidade de encontrar um fundamento teórico-crítico para a educação em direitos humanos, buscando novas formas de investigação e de análise para sua compreensão. É o que tentaremos fazer ao longo desse caminhar reflexivo.

\section{Teoria e Pedagogia Críticas}

Embora Bobbio (2004, p. 45) já tenha afirmado que o problema dos direitos humanos não é tanto filosófico, "mas jurídico e, num sentido mais amplo, político", que não é tanto a questão de encontrar seus fundamentos, mas de garantir sua realização, impedindo que sejam violados, há preocupações que envolvem professores e professoras que orientam seu trabalho educativo em e para os Direitos Humanos. Que fundamento/s pode/m explicar, iluminar a mediação pedagógica em e para os Direitos Humanos? Que perspectivas, conceitos e abordagens darão conta da complexidade de uma educação em e para os Direitos Humanos e da complexidade da vida cotidiana? Encontrar esses fundamentos é uma tarefa bem mais complexa dos que podemos imaginar, considerando a provisoriedade do conhecimento e da vida sempre em processo, as múltiplas e dinâmicas relações sociais, os contextos de formação.

Não estamos afirmando a necessidade de abandonar conceituações, métodos e abordagens anteriores, mas procurar compreender e analisar em que podem ajudarnos a trabalhar a educação em direitos humanos. Desde logo, afirmamos que somente uma abordagem multidimensional e multimetodológica contribui como fundamento e orientação para a educação em e para os direitos humanos, pela sua própria abrangência e complexidade. Essa preocupação trará para estudo aspectos emocionais, afetivos, valores que marcam o comportamento humano, colocando lado a lado o individual e o social, o racional e o irracional, a ordem e o conflito, o estático e o dinâmico.

Estamos, na verdade, buscando pensar um espaço pedagógico em que professores e professoras, alunos e alunas sejam capazes de questionar e discutir, "de maneira ativa, a relação entre a teoria e a prática, entre a análise crítica e o sentido comum, entre a aprendizagem e a mudança social". (GIROUX, 2008, p. 17). Todos esses fatores necessitam de ser considerados em face das mudanças efetivadas nas condições sociais e informacionais do final do século XX e início do século XXI, da complexidade contextual desse início de século, em que não existem respostas simples e acabadas para questões sobre justiça, democracia, aprendizagem, prática educativa. 
Em vista das questões colocadas, retomamos a indagação que norteia nossa reflexão: Que fundamento/s pode/m explicar, iluminar a mediação pedagógica em e para os Direitos Humanos? Respondemos, orientados pelos estudos de Kincheloe (2008), que para dar conta da complexidade que se processa, são necessárias novas formas de investigação e de análise, baseadas em um criticismo em evolução.

Nesse sentido, tanto a Teoria Crítica como a Pedagogia Crítica estão em constante evolução, modificando-se a partir de novas ideias, novos problemas, novos contextos. Nutrindo-se de uma diversidade de discursos, a partir da Escola de Frankfurt de Teoria Social, esse criticismo tem procurado compreender não só as diversas formas de opressão e de dominação, mas também desvelar mistificações ideológicas nas relações sociais.

Assim, o poder como forma de dominação tem sido uma das preocupações centrais da teoria critica, sendo urgente compreendê-lo, desvendá-lo, conhecêlo em suas formas, como acontece com a meta-aprendizagem, desvelada em sua articulação com o poder e com a dominação.

Um criticismo em evolução dispõe de mecanismos necessários para desmascarar políticas de poder e opressão favoráveis ao "privilégio branco, masculino, elitista, heterosexual, imperialista e colonial" e, para criticar o eurocentrismo, assim como todas as formas de privilégio e opressão: sociais, econômicas, políticas, epistemológicas, culturais, ideológicas.

Por outro lado, a natureza interdisciplinar da teoria crítica fomenta a interconexão entre as diversas áreas do conhecimento, entrecruzando objetos de estudo, articulando teoria e prática, desafiando convenções estabelecidas.

A Teoria Crítica constitui um desafio às grandes narrativas, como "o capitalismo, o racionalismo científico, a burocracia, os valores burgueses, o colonialismo, o patriarcalismo, o cristianismo, o liberalismo e a corporatização",e o determinismo, optando pelas "histórias de luta, de exclusão, de marginalização, de abusos, de falta de ação e de outras injustiças sociais que contrastam com os poderes discursivos" (BERRY, 2008, p. 117) das grandes histórias. De fato, o cenário atual ainda configura-se como o das grandes histórias, como cenário das construções eurocêntricas e ocidentais; porém, o espaço crítico está-se alargando e podemos ter esperança (no sentido freireano) de justiça social, igualdade, diversidade, pluralidade e inclusão, como reivindicações da perspectiva crítica. "A esperança é o desejo de sonhar, o desejo de mudar, o desejo de melhorar a existência humana". (LEISTYNA, 2008, p. 141).

A Teoria e as Pedagogias Criticas compreendem o conhecimento como processo, fomentam trocas sociais e culturais, permitindo o desvelamento 
de mecanismos e estruturas de poder (social, política, econômica, cultural e educacional), desenvolvendo-se e atuando para "obter uma compreensão mais sofisticada do mundo e do ato educativo", não devendo "perder nunca de vista que sua preocupação fundamental é o sofrimento humano". (KINCHELOE, 2008, p. 40). E esse sofrimento ocorre em consequência ao desrespeito e como forma de violência aos Direitos Humanos.

A essa configuração do sofrimento humano um criticismo em evolução pode responder com novas formas de educação e de intervenção, o que abre espaço para novas perspectivas educacionais como é o caso de uma educação crítica em e para os direitos humanos.

Para a era em que vivemos, Kincheloe (2008, p. 42-46) apresenta os aspectos fundamentais da Teoria Crítica, e que, em nossa compreensão, podem alicerçar a Educação em Direitos Humanos, lembrando, no entanto, a característica "em evolução" da Teoria e da Pedagogia Crítica, significando que, pela mutabilidade, mobilidade e dinamicidade que lhes são próprias, o que é fundamental em determinado período pode perder essa característica em outro.

Considerando esse ponto de vista, apontamos a rejeição ao determinismo econômico como um dos fundamentos da teoria crítica, o que significa que esta não assume a tese do marxismo de que todos os aspectos da vida humana são determinados pelos fatores econômicos. Ora, um criticismo em evolução considera todos os fatores e suas diversas formas de dominação, todos os eixos em que se movimenta o poder, inclusive o econômico. Esse conceito não perde de vista o contexto atual. Uma época de política "neoliberal desumanizadora que tem originado o sofrimento de muitas pessoas e o enriquecimento de umas poucas e que, em consequência, está afetando as condições de vida de milhões de pessoas em todo o mundo". (HUERTA-CHARLES, 2008, p. 305). A Teoria Crítica contribui para a desconstrução de ideias e conceitos prontos e estabelecidos. Se a ideia de determinação econômica serviu ou justificou um momento histórico da vida cotidiana, já não responde ou explica a complexidade desse início de século XXI.

A critica da racionalidade instrumental ou técnica é outro fundamento de um criticismo em evolução que rejeita a relevância dos meios em detrimento dos fins, porque considera essa racionalidade como um dos aspectos mais opressivos da sociedade contemporânea. Nesse sentido, a rejeição por esse fator marcante encontra explicação no privilégio ao método e a eficiência do que aos resultados. 0 que interessa é se a trajetória foi bem traçada e não os propósitos que serão alcançados, verificando o privilégio a técnica em detrimento do humano. 
Outro conceito importante, utilizado pela Teoria Crítica, é o impacto do desejo, configurado a partir da valorização da psicoanálise pós-estrutural, contributo importante para uma proposta de emancipação social. A psicoanálise pós-estrutural possibilita aos investigadores críticos compreenderem os processos inconscientes de resistência a mudança, como também o desejo de resistência à opressão, o empenho em projetos emancipatórios, significando que o psiquismo interage com o sociopolítico, não havendo por que separá-los em esferas diversas. "[...] ao dedicar-se ao desejo e a vitalidade da vida cotidiana, ao discernir o modo em que devem utilizar-se de um modo emancipatório e não manipulador, a autorrealização reexamina a relação entre o eu e o entorno" (KINCHELOE, 2008, p. 61). Nessa interação entre o eu e o social, "[...] o eu se acopla a outros eus em uma união sólida que constrói uma nova visão para uma prática crítica revigorada e em contínua evolução." (KINCHELOE, 2008, p. 61).

Nesse contexto de alicerces críticos, vislumbra-se o conceito de imanência que permite o desejo pelo que poderia ser. Um criticismo em evolução, motivado pelo espírito freireano (aqui privilegiado) e a partir da compreensão de imanência, sonha formas de diminuir o sofrimento humano, e que, no âmbito educacional, consubstanciar-se-ia em uma pedagogia como prática da liberdade, uma pedagogia crítica, com professores e professoras como agentes de mudança social.

A categoria crítica do poder reconceitualizado como hegemonia visa compreender o comportamento do poder, as formas e modos como opera para conseguir o consentimento dos subordinados e exercer a dominação. Na concepção de poder como instrumento de opressão, de provocador de desigualdades e de sofrimento, a noção de hegemonia, designadamente a gramsciana, contribui para a compreensão de que o poder é exercido não somente pela força física, mas também através da psicologia social. Compreender essa forma de dominação consentida é um processo complexo e importante para uma teoria crítica em evolução. 0 poder atua de muitas formas, "para construir identidades, para outorgar poderes e para oprimir a grupos determinados [...]" (KINCHELOE, 2008, p. 35), mas sempre com o propósito de normalizar o indivíduo para ajustá-lo à ordem social vigente.

Uma Teoria Crítica do poder compreende, além disso, a produção da ideologia como o outro lado da hegemonia. A ideologia hegemônica comporta "as formas culturais, os significados, os rituais, e as representações que criam o consentimento tanto para o status quo como para o lugar concreto" ocupado por cada indivíduo. (KINCHELOE, 2008, p. 44).

A Teoria Crítica percebe ainda o grande poder da linguagem como instrumento de dominação e regulação social. A linguagem não é uma prática neutra e objetiva, mas variável em seus significados a partir dos contextos em que é desenvolvida. Por não ser uma prática neutra, ela pode ser utilizada a favor ou contra projetos progressistas, como regulação e dominação ou como construção de uma sociedade mais humanizada. 
Outro aspecto fundamental abordado pelo criticismo diz respeito à relação entre cultura, poder e dominação, considerando que a cultura é um espaço de luta e que é inegável o conflito entre cultura dominante e subordinada na produção e transmissão do conhecimento. E aqui, a cultura popular se tem colocado como importante temática para a investigação critica sobre o poder e a dominação.

A Teoria Crítica valoriza a hermenêutica crítica como forma de interpretação não do fato pelo fato, mas no sentido de atribuir um significado mais amplo ao observado, considerando todos os aspectos possiveis do objeto de investigação, configurando-o em sua conplexidade, pela própria razão de que esse intento de compreensão da realidade e do conhecimento é fundamental para nossa vida.

Nesse sentido, uma hermenêutica crítica contribui para a compreensão das formas de opressão e de dominação presentes em nosso contexto histórico, favorecendo a produção de uma sociedade mais justa, democrática e igualitária.

Um criticismo em evolução afirma também que não existe neutralidade na educação nem tampouco no trabalho do professor. A prática pedagógica docente, as posturas e ações são sempre politicas e intervencionistas, tendo em vista os "[...] efeitos que produz sobre o conhecimento, nas experiências que organiza nas aulas e no futuro que antecipa nos inumeráveis modos em que se enfrenta o mundo." (GIROUX, 2008, p. 19).

Os educadores e educadoras como participantes de seu momento histórico, envolvidos nas condições sociais, políticas e econômicas de sua existência não poderão apartar-se dessas condições no exercício professoral, trazendo para a educação a articulação com o mundo, vivenciando a pedagogia como prática moral e política.

Nesse sentido, uma prática pedagógica critica deve proporcionar a alunos e a alunas a aprendizagem da reflexão e da escolha, importantes ferramentas para a conquista da autonomia, para a tomada de decisões que provocam mudanças na sociedade para o funcionamento da democracia.

A teoria crítica também está preocupada com a justiça social (e com a justiça educativa), não como meio ou fim, mas como processo que se movimenta para a construção de condições universais, como processo interminável, pelo próprio fato da humanidade materializar-se em contextos e momentos diversificados, e para que essa justiça tenha relação com a vida cotidiana, com os oprimidos do mundo. Porém, para que educadores e educadoras se transformem em agentes de justiça social precisam compreender a complexidade dos domínios social, político, psicológico e educacional, em sua articulação com a vida humana, fazendo-se necessária a criação de alternativas democráticas, de 
processos educacionais que contribuam para que individuos concretos possam identificar/compreender a opressão de que são vítimas e reconstruam sua consciência emancipatória e sua identidade.

A Pedagogia Critica nutre-se do pensamento pedagógico de muitos autores críticos, mas, neste trabalho, destacamos de modo particular, como já dissemos, o pensamento freireano como teoria e prática transformadora. A tradição pedagógica freireana, comprometida com processos de desenvolvimento crítico das subjetividades para a ação política, atualiza-se em uma Pedagogia Crítica complexa, configurada como um desafio ao estabelecido, ao pensamento, às ideias e às práticas pedagógicas dominantes, às relações educacionais e sociais de dominação, apresentando outras lentes para ver, ouvir e compreender o ato educativo em seus contextos e momentos históricos. Dai sua articulação com os Direitos Humanos, sua possivel contribuição como fundamento para uma prática pedagógica em e para os Direitos Humanos.

$\mathrm{Na}$ abordagem crítica, a educação é ainda compreendida como espaço de reconstrução e de possibilidade transformadora, enxergando-se um compromisso com o fortalecimento da democracia, enquanto "espaço alargado de participação e de tomada de decisões". (SILVA, 1999, p. 73).

Por seu turno, a Pedagogia Crítica possibilita aos educadores expressarem sua indignação frente às injustiças do mundo, criando-se nas escolas e nas Universidades um espaço de discussão e desenvolvimento de uma prática política e moral, que oriente os alunos e alunas a assumirem seu poder como agentes criticos, proporcionando um espaço educativo de liberdade para refletirem, questionarem, afirmarem e decidirem.

A Pedagogia Crítica exige igualmente sensibilidade ao sofrimento humano por parte de professores e professoras, sendo nessa perspectiva que Paulo Freire utilizou, no final dos anos 1950 e no início dos anos 1960, no Brasil, seus pressupostos nas experiências com a educação de adultos. Essa população educacional reprimida e subjugada, tanto pelas condições sociais de existência como pelo analfabetismo, teve acesso a um processo de socialização do conhecimento e da cultura, adquirindo uma consciência crítica de sua própria existência, ferramenta importante para a atuação na sociedade. Naquele momento, a educação fomentava relações de poder e dominação injustas e desiguais, reproduzindo ideologias e tradições dominantes, controlando contextos e valores, ignorando interesses, contextos, valores e propósitos individuais e coletivos das populações oprimidas.

Para esse contexto de opressão, a Pedagogia Crítica freireana proporcionou uma prática educativa para a libertação, ensinando os alicerces básicos para que alunos e alunas adultos, trabalhadores e trabalhadoras superassem a alienação política. 
Considerando as condições atuais da existência humana e os desafios de uma nova era, ou de uma "era sem nome", como afirma Kincheloe (2008, p. 40), em que a miséria, a opressão e a exclusão assumiram uma outra face ou se transmutaram, mas que massacram, desumanizam os miseráveis do mundo, é preciso refletir sobre que opção pedagógica assumir, pôr em prática.Compreendemos que para esse novo contexto, faz-se necessária uma proposta pedagógica que envolva os saberes das populações subjugadas e reprimidas em um movimento interativo com perspectivas, saberes, conhecimentos sistematizados importantes tanto para a prática pedagógica como para a ação política. Uma proposta que ensine a elaboração de novas questões e de novas estratégias que tornem possíveis não só a compreensão desse contexto, mas também uma ação consciente para melhorá-lo. Uma proposta que abranja a articulação entre o social e o individual, entre o macro e o micro, entre o eu e 0 outro, desenvolvendo alternativas para um comportamento fraterno entre os povos.

Nessa perspectiva, uma Pedagogia Crítica que contribua para a prática pedagógica em e para os Direitos Humanos necessita apresentar um criticismo em evolução, nutrido de variados discursos críticos e de tradições teóricas, "surgidos a partir da Escola de Frankfurt", para a compreensão das diversas formas de opressão "por motivos de raça, gênero, orientação sexual, cultura, religião, colonialismo e assuntos relacionados com as capacidades" (KINCHELOE, 2008, 38).

Considerando essa preocupação e com o propósito de discutir pressupostos teóricos críticos para uma prática educativa em direitos humanos e de compreender a potencialização da Pedagogia Crítica para dinamização e revitalização teóricas do campo educacional dos Direitos Humanos, vamos, em seguida, aprofundar esse tópico.

\section{Pressupostos Críticos para uma Educação em/para os Direitos Humanos}

$\mathrm{Na}$ compreensão de Kincheloe (2008, p. 61), "para operar no estranho cenário sociocultural" do século XXI, a consciência contextual é importante, contribuindo para o processo evolutivo desses pressupostos, os quais, partindo da tradição teórico-crítica, atualizam-se em uma Pedagogia Crítica em evolução, assumindo um novo sentido.

Nessa perspectiva, e buscando refletir sobre os contributos da Teoria e da Pedagogia Críticas, sobre a forma de como esses marcos conceituais podem iluminar a prática educativa em Direitos Humanos, temos um questionamento latente desde o início da discussão: em que sentido os princípios que alicerçam a Pedagogia Crítica se articulam com os princípios de Direitos Humanos, tendo em vista que os Direitos Humanos são processos, movimentos sociais e educacionais pela vida e pela continuidade/ construção da vida com dignidade? Assim sendo, em que sentido a Pedagogia Crítica pode contribuir para orientar práticas educativas de inclusão e de justiça social? 
Procuramos dar continuidade a essa reflexão tentando compreender alguns pressupostos da Pedagogia Crítica como, conscientização, criticidade, politicidade, poder e resistência, emancipação e empoderamento, autonomia, democracia e participação, dialogicidade e historicidade, abordando estudos e conceitos de Freire $(1993,2000,2002,2004,2011)$ e de outros críticos como Giroux (1983, 1994, 2008), McLaren (2008), Kincheloe (2008) e Apple (1998).

Nos estudos desses autores, percebemos uma luz para guiar nossa trajetória reflexiva, tendo em vista que a proposta pedagógico-critica deve ser vista como inacabada ou em construção, considerando o caráter constante de reformulação e desenvolvimento do pensamento e da prática críticos, e no mesmo sentido, que a "teoria crítica nunca estará concluída, sempre será uma opção aberta, uma teoria em construção" (ANDRADE, 2006, p. 68). Ou ainda, esses estudos serão uma inspiração, podendo ser criada uma nova síntese, como fez Freire, quando reconstruiu e retrabalhou suas ideias e a de outros estudiosos. No dizer de Apple (1998, p. 44), "Esta é também, [...], a nossa tarefa. Também nós devemos tomar Paulo Freire com todas as contradições e complexidades do seu trabalho, retrabalhá-lo à luz de novas circunstâncias históricas emergentes e permanecer aos seus ombros".

Por outro lado, um aspecto que não podemos esquecer é que as teorias, as práticas educativas, as ideias, as palavras encontram-se marcadas pelas condições históricas que Ihes dão origem, o que não impede que suas implicações sociais e políticas gerem possibilidades de libertação para todos os povos dominados. É nessa conformação que o pensamento freireano está impregnado pelas condições históricas brasileiras de sua época, mas perfeitamente atualizado às condições históricas atuais.

A metáfora freireana sobre o que é ensinar ${ }^{2}$ orienta para o trabalho educacional como atividade de conscientização, percebendo-se a importância do papel do professor nesse processo. Ele é responsável por ensinar a pensar criticamente. Nesse contexto, compreendemos a contribuição dos princípios da conscientização e da criticidade para o trabalho em e para os Direitos Humanos. Os professores não devem depositar pacotes de conteúdo na consciência vazia dos alunos, em outras palavras, os professores devem formar/desenvolver habilidades de reflexão e crítica, ativando as ideias, o olhar, os ouvidos e a sensibilidade dos alunos para a compreensão da vida, da realidade, dos saberes e conhecimentos postos em diálogo. É nesse sentido a compreensão de McLaren (2008, p. 410) sobre os ensinamentos freireanos: "Freire nos recorda que o ensino não pode reduzir-se a uma transmissão unidirecional do objeto, nem a uma transação bidirecional entre o professor ou professora e o aluno ou aluna".

2 Ensinar “[...] não é depositar pacotes de conteúdo na consciência vazia dos alunos” (FREIRE, 1993, p. 27). 
Adepto da teoria crítica, Freire utiliza seus pressupostos e ensinamentos para a criação de uma Pedagogia Crítica, tomando a consciência crítica como princípio problematizador das relações sociais de poder e opressão, entre outros princípios críticos incorporados ao pensamento e à prática pedagógica. No trabalho com adultos, Freire tinha o propósito de desenvolver uma consciência crítica para a promoção da ação social, com vistas à superação de estruturas sociais injustas. Em seu propósito educacional estava incluso o combate a formas de exclusão e desigualdade, o desejo de emancipar o homem de injustiças e de estruturas sociais dominantes. Dai a necessidade do trabalho de conscientização pela educação. Assim, resultantes do trabalho freireano, temos uma "educação para a problematização e uma metodologia de investigação temática" (TORRES, 2003, p. 212) que podem ser aplicadas não apenas na educação de jovens e adultos, mas em áreas diversas do conhecimento, inclusive na educação em direitos humanos.

A Educação em e para os Direitos Humanos exige a compreensão da realidade micro e macro, sua análise crítica, o entendimento de processos interdisciplinares que integram vários campos do conhecimento, a preparação de uma base teórica para a ação e intervenção social. Porque tanto a aquisição de conhecimentos e saberes como a consciência crítica são necessárias "para compreender e questionar padrões opressores de organização social, política e econômica" (MEINTJES, 2007, p. 122). Colocando-se entre verdade e utopia, a Pedagogia Crítica freireana define como princípio fundamental da prática pedagógica a conscientização do oprimido, colocando a escola e o educador como mediadores desse processo. Seu pensamento configura-se como eminentemente político, postulando em seus trabalhos que não existe revolução educacional sem revolução política. 0 que isso significa? Que programas e projetos educacionais podem ser desenvolvidos para a organização popular, que a consciência política contribui para a consciência de classe e para a reivindicação por direitos.

Nesse sentido, o pressuposto da politicidade implica na consciência política que conduz a ação em termos concretos. 0 processo de politização em Direitos Humanos conforma a aprendizagem "da pronúncia do mundo", empoderando a vítima da compreensão da dominação e das possibilidades de emancipação, ou seja, como pode intervir na realidade para modificar sua situação de dominado. Ao convidar professores e estudantes para serem alfabetizados políticos, Freire transpõe seu momento histórico, contemplando todas as formas de dominação. Para ser um alfabetizado político, dado seu inacabamento, é necessário estar sempre aprendendo e melhorando, porque onde há vida há inacabamento, porque só os seres que se tornaram éticos, podem romper com a ética (FREIRE, 2002).

Aqui lembramos as pesquisas de iniciação científica que realizamos sobre os movimentos de Educação popular do início dos anos $1960^{3}$. Em Angicos/RN, vimos a

\footnotetext{
${ }^{3}$ Estamos falando, principalmente, da pesquisa de Iniciação Científica/UFPB, realizada no período de 2010 a 2011, sobre o projeto de educação popular desenvolvido na cidade de Angicos/RN/Brasil, denominada "Educação de jovens e adultos em 40 horas: Angicos/RN - 1963 (história e memórias)."
} 
carta que a participante do projeto de alfabetização de adultos enviou ao Presidente João Goulart, em março de 1963, em que reivindicava sua condição de pessoa humana, configurando-se o pressuposto da conscientização, da politização, como condição para a conquista da dignidade humana. Tal princípio da pedagogia critica projeta-se como fundamento para a Educação em Direitos Humanos. Vejamos nas próprias palavras de Freire (1994, p. 145):

Quando um analfabeto de Angicos, falando frente ao Presidente Goulart [...] declarou que já não era massa, mas gente, não se tratava apenas de uma frase: ele conscienciosamente afirmava uma opção. Escolheu a participação decisiva que só as pessoas têm, e rejeitou a dimensão emocional de massas. Estava politizado.

Podemos perceber nesse alfabetizado político que ele apreendeu as habilidades necessárias ao sujeito de direitos. Ora, vemos em sua declaração as marcas da consciência e do empoderamento que transformam o oprimido, o injustiçado em um sujeito de direitos. Ele diz não à condição de massa, afirmando ser gente, povo, sujeito único, inconfundivel, sujeito de direitos; também diz não às arbitrariedades e abusos possiveis a sua dignidade; e ainda, nega a condição de vítima, libertando-se da dominação, emancipando-se pelo questionamento, pela compreensão e pela consciência, problematizando o sentido da dominação, das injustiças e da justiça e também da consciência. 0 alfabetizado angicano descobriu as possibilidades de agir em sua vida e na realidade.

Nesse sentido e para além de Freire, no momento histórico em que vivemos, compreendemos a necessidade de conscientizar em Direitos Humanos não só o oprimido, tendo em vista que os DH estão preocupados com a conscientização de todos os seres humanos sobre seus direitos, defesa e proteção, compreendendo que todos são vulneráveis à violência e à anulação dos direitos de cidadania, ou seja, pela própria dinamicidade e processo histórico em que são construídos os direitos e a cidadania, todas as pessoas, tendo em vista sua circunstância histórica, ao longo do tempo tanto podem tornar-se vulneráveis, destituídas de cidadania como "podem tornar-se suscetíveis ao seu pleno exercício" (MEINTJES, 2007, p. 124).

Face ao exposto, uma consciência critica possibilita aos individuos superar a alienação da sociedade de consumo, pelo conhecimento das condições sociais e de autoprodução em que vivem. Fortalecidos com esses conhecimentos, "os individuos com uma consciência crítica são capazes de utilizar suas perspectivas para superar a alienação e construir relações sociais e individuais com outros agentes sociais" (KINCHELOE, 2008, p. 64).

Nessa configuração, devemos compreender conscientização e criticidade desde sempre em articulação. 0 indivíduo compreende a realidade pela consciência crítica em superação à visão ingênua, ou seja, partindo da realidade em que se encontra, compreende e explica as razões que esclarecem sua condição de "oprimido". 
"Segundo Freire, chega-se a esse momento pela análise teórica das causas da opressão" (ANDRADE, 2006, p. 343), pela explicação e pela crítica, sendo necessária, para tanto, uma educação que prepare para o questionamento de sua condição. É a conscientização pela educação que opera a compreensão das injustiças sociais, projetando-se para a decisão e para a ação. "E esta conscientização muitas vezes significa o começo da busca de uma posição de luta" (WEFFORT, 2011, p. 15).

Nesse sentido, "[...] a visão educacional não pode deixar de ser, ao mesmo tempo, uma crítica da opressão real em que vivem os homens e uma expressão de sua luta por libertar-se" (WEFFORT, 2011, p. 14). Uma Educação em Direitos Humanos pode fornecer as bases teóricas e prática para a defesa de direitos e para a consciência de sua violação.

Em seus contributos, a Pedagogia Crítica poderá fortalecer a EDH pelo fato de estimular tanto a crítica como a ação, por meio de uma linguagem de ceticismo e possibilidade, e mediante uma cultura de abertura, debate e compromisso, elementos que na atualidade se encontram em perigo (GIROUX, 2008). A Pedagogia Crítica contribui para que professores e professoras assumam sua responsabilidade política perante a educação e a sociedade, para que meditem sobre seu papel de educadores de alunos e alunas, que precisam ser orientados para além dos conhecimentos estabelecidos como verdades absolutas ou "certezas totalizantes" (FREIRE, 1993). A pedagogia como espaço de debate possibilita que educandos não só assimilem criticamente as ideias, mas que atuem sobre elas e as transformem.

Partindo dessa compreensão, a prática pedagógica que tem a Pedagogia Crítica como pressuposto, além de ensinar aos alunos e alunas o conhecimento e o exercício de atividades críticas, proporciona os fundamentos para que aprendam não só a ser governados, mas que também sejam capazes de governar e, sobretudo, que aprendam práticas de respeito e solidariedade.

A Pedagogia Crítica compreende e critica, como vimos, os complexos mecanismos de poder e opressão em um sistema global de desigualdades, dispondo de ferramentas para desmascarar políticas de poder e desigualdade e de práticas pedagógicas e políticas para impedir/enfrentar seus efeitos. Compreendendo os emaranhados do poder e de seus efeitos quer sobre a sociedade, quer sobre os indivíduos em particular, a partir da problematização da realidade, de uma reflexão teórica e contextual interessada, o indivíduo poderá organizar formas de resistência e enfrentamento, resistindo a uma política da intolerância, da divisão e da exclusão.

Nas situações de sala de aula, os efeitos do poder nas relações sociais não podem ser ignorados. 0 conhecimento deverá ser abordado como objeto de indagação crítica, tratando a essência do próprio conhecimento no âmbito das relações que Ihe dão significado, como forma de preparação para intervenção ou resistência. 
Porque, a partir do momento em que pensamos a universidade e a escola como espaços de criação de novas formas de saberes e de sensibilidades, de experiências e de sociabilidade, implica que pensemos em formas de resistência para defesa mesmo da vida humana. Por essa razão, uma pedagogia para os Direitos Humanos encontra eco na pedagogia freireana.

Nesse sentido, enxergamos a necessidade das orientações de uma Pedagogia Crítica para os Direitos Humanos, uma pedagogia ativa, que nos ensine "que ao desumanizar ao outro nos desumanizamos a nós mesmos", que nos conduza à "reapropriação de nossa dignidade em perigo, até a restituição de nossa humanidade" (ANDRADE, 2006, p. 331).

Dentre os princípios fundamentais da Pedagogia Crítica que podem contribuir como fundamento para uma Educação em e para os Direitos Humanos, além da consciência crítica, tão valorizada por Freire em seus estudos e prática pedagógico-política, e dos já abordados nessa reflexão, sinalizamos a emancipação crítica e o empoderamento.

A emancipação como categoria crítica deve ser pensada a partir de uma relação intersubjetiva marcada pela diversidade e pela pluralidade, que dão origem a relações conflituosas, mas que podem gerar possibilidades emancipatórias, compreendendose que os sujeitos livres e autônomos são a base da emancipação.

Com fundamento nessas noções iniciais sobre emancipação e autonomia, apostamos em uma nova subjetividade para os Direitos Humanos, aberta, interrelacional e em construção. A emancipação crítica como conceito e mecanismo de ação política articula-se com os propósitos pedagógicos da Educação em e para os Direitos Humanos, desvendando as forças que impedem os indivíduos de participarem das decisões que afetam suas vidas. Ou nas palavras de Kincheloe (2008, p. 42): "Aqueles e aquelas que buscam a emancipação tentam conseguir o poder de controlar suas próprias vidas em solidariedade com uma comunidade orientada para a justiça. [...] Desse modo se podem conseguir níveis maiores de autonomia e de ação humana".

0 autor alerta também para a questão de que devemos ter cuidado com a utilização do termo emancipação, partindo da compreensão de que ninguém pode emancipar-se completamente do seu contexto sociopolítico.

No mesmo sentido, Magendzo (2012, p. 1) afirma que emancipação é um "processo através do qual as pessoas oprimidas e exploradas constituem-se em sujeitos empoderados capazes de transformar, por seus próprios meios, suas circunstâncias". Porque, a partir do interesse emancipatório, e orientado pelo conhecimento, o sujeito questiona o poder como dominação, buscando emancipar-se das forças reificadas. "Uma ferramenta-chave para a produção desta emancipação 
é a autorreflexão. [...] o que se procura é uma libertação da alienação humana por meio de uma iluminação crescente através da análise, da explicaçãoe da construção do conhecimento." (TORRES, 2003, p. 120).

Nesse contexto, lembramos os propósitos da Teoria e da Pedagogia Crítica que dizem respeito à criação de uma sociedade mais justa e ao empoderamento das pessoas, o que significa um "maior controle sobre suas vidas econômicas, políticas, sociais e culturais" (MAGENDZO, 2012, p. 01).

Considerando essa perspectiva educacional, a EDH assume a natureza de uma prática política dialógica, formadora do processo de autonomia dos sujeitos de direito. Chegamos à autonomia pelo debate, pela interrogação e pela reflexão. Uma Pedagogia Crítica considera a liberdade de escolher, de expressar-se, de tomar decisões, habilidades que podem contribuir para a autonomia individual e coletiva, para a formação de sujeitos responsáveis em suas decisões e coerentes em suas escolhas.

Segundo Kincheloe (2008, p. 65), "A importância da existência relacional, em uma sociedade democrática não é somente intrínseca; também inclui benefícios cognitivos e educativos para o autodesenvolvimento". Nesse sentido, a aprendizagem deve ser reelaborada na intenção de favorecimento das relações democráticas, para que professores e alunos possam atuar como cidadãos em um espaço de intercâmbio de ideias e produção de consciência. "Deste modo, a pedagogia crítica vem encarnar o processo de democratização radical, o intento continuado dos atualmente excluídos e excluídas para adquirir o direito e a capacidade de participar da vida cívica" (KINCHELOE, 2008, p. 66).

Os ensinamentos de Freire (2002) expressam a responsabilidade do professor nessa empreitada para a possibilidade de mudança, para a importância de sua tarefa político-pedagógica, para o reconhecimento de que a prática pedagógica é política e diretiva, não existindo uma prática educativa neutra.

Para compreendermos a importância de uma vivência democrática para a consecução dos Direitos Humanos, trazemos as palavras de Bobbio $(2004$, p. 21) que explicam por si mesmas a interrelação indissolúvel entre democracia, paz e Direitos Humanos como "três momentos necessários do mesmo movimento histórico: sem direitos do homem reconhecidos e protegidos, não há democracia; sem democracia, não existem as condições mínimas para a solução pacífica dos conflitos".

Considerando essa fundamentação teórica, professores e professoras, alunos e alunas necessitariam estar preparados para a participação nos processos democráticos da cidadania ativa, de respeito ao diferente, oportunizados por uma prática político-pedagógica democrática. Freire $(2002$, p. 136) ensina que 0 
desenvolvimento de uma prática democrática exige virtudes como "amorosidade, respeito aos outros, tolerância, humildade, gosto pela alegria, abertura ao novo, disponibilidade à mudança, persistência na luta, recusa aos formalismos, identificação com a esperança, abertura à justiça", ensinando ainda que essa prática não se faz apenas com ciência e técnica.

No respeito ao outro e à diferença do outro, situamos a prática dialógica tão importante à Pedagogia Crítica e ao pensamento freireano. Se não reconhecemos como outro a criança pobre, negra, rica, índia, a mulher, o operário, desconhecimento que nos orienta para a discriminação e desrespeito, não escutamos e não respeitamos aqueles que pensam e constroem suas ideias de maneira diferente ou contraditória ao nosso discurso.

A sensibilidade e o diálogo, alicerces da Pedagogia Crítica para a prática pedagógica, transformam-se em condições necessárias para a prática pedagógica em Direitos Humanos. A EDH possibilita uma sensibilização e conscientização das pessoas para a importância do respeito ao diferente, tornando-se um instrumento fundamental na construção da formação cidadã para a afirmação dos Direitos Humanos. E essa sensibilização e uma conscientização só podem ser ensinadas/aprendidas pelo diálogo, pela abertura respeitosa ao outro, pela sensibilidade do ouvir, do escutar, em um movimento dialógico permanente.

A EDH, como prática educativa crítica, deve ter por propósito desenvolver nos alunos e alunas, nos indivíduos e nos povos as capacidades para se realizarem como sujeito de direitos, pela atuação na formação do ser humano em todas as dimensões, proporcionando as condições necessárias para a efetivação da sua condição cidadã e da sua humanidade. Nesse contexto de ensino-aprendizagem, o diálogo constitui-se uma ferramenta para conscientização, para a construção crítica.

Precisamos lembrar, nesse momento, o contexto que deu origem a EDH, principalmente na América Latina e que reflete, entre outras, a dimensão política da EDH. Surgiu em um cenário de lutas sociais, de movimentos emancipatórios, e a partir do enfoque freireano, "no qual através do diálogo as pessoas aprendem e tomam consciência de que são sujeitos de direito e aprendem como trabalhar por sua própria libertação" (MAGENDZO, 2012, p. 2-3).

Essa forma de educação orienta para o discernimento das questões que estão na base, nas entrelinhas ou nas lacunas das injustiças sociais, para um maior controle das pessoas sobre suas vidas e sobre a realidade. Ou no entendimento de Magendzo (2012, p. 4): "A emancipação surge da autoconsciência da coerção escondida e das ações libertadoras incorporadas na pedagogia crítica". 
Se voltarmos nossa atenção para a questão histórica, observaremos as similitudes e relações entre a Pedagogia Crítica e a EDH. Na explicação de Magendzo (2012, p. 7): "[...] tanto a Pedagogia Crítica como a Educação em Direitos Humanos se relacionam com a injustiça social, a opressão e a violência e que são o resultado de lutas intensas e incessantes das pessoas para tornarem realidade seus direitos. Esta luta está cheia de contradições e conflitos".

Porque pensamos uma Pedagogia Crítica para os Direitos Humanos, pensamos em uma prática do compromisso com a experiência e a história de cada um, dialeticamente interpretada em oposição à totalidade que lhe deu origem.

Dessa prática educativo-crítica surge o sujeito pedagógico, que se constitui como sujeito histórico pela consciência crítica de sua situação no mundo. "O sujeito pedagógico é um sujeito histórico, que concebe a realidade como realidade histórica e a inteligência histórica como possibilidade" (FREIRE apud ANDRADE, 2006, p. 344), porque a história não é senão a atividade do homem que persegue seus objetivos. A historicidade presente nos trabalhos freireanos aponta para a possibilidade de transformação do presente, pelo fato de compreendê-lo dialeticamente, como algo dado e também como espaço de possibilidades libertadoras.

Uma prática educativa para os Direitos Humanos, baseada nos princípios da Teoria e da Pedagogia Críticas, necessita lutar pela construção de uma utopia, uma utopia concreta, vinculada ao presente, e acreditar nela em oposição a uma utopia abstrata. Essa utopia tem origem na tensão entre "[...] a denúncia de um presente que é cada vez mais intolerável e a anunciação de um futuro que teremos que criar, que construir [...], as mulheres e os homens" (FREIRE, 2004, p. 91).

\section{Outras Implicações da Educação para os Direitos Humanos numa Perspectiva Crítica}

Os professores e professoras que acreditam em uma perspectiva crítica para a Educação em e para os Direitos Humanos deve utilizar-se de principios da Pedagogia Crítica e articulá-los aos princípios e propósitos da EDH. Nesse sentido, deve ser considerada a interrelação entre justiça social, respeito à dignidade humana, solidariedade, diversidade e conscientização, diálogo, emancipação, pois esses princípios, e em particular o princípio da conscientização "tem vigência para qualquer tipo de aprendizado" (WEFFORT, 2011, p. 11). É desse modo que eles podem contribuir para o desenvolvimento de uma prática pedagógica em DH. Tomando a conscientização como matriz, ela pode ser trabalhada para a prática cidadã, para a autonomia de direitos, na medida em que proporcione momentos de participação livre e critica de alunos e professores. 
Nesse espaço de ensino e aprendizagem, consciência, diálogo, conhecimentos, experiências cruzam-se, conectam-se. 0 diálogo proporciona a compreensão da violência sofrida, do desrespeito aos $\mathrm{DH}$, gerando a indignação, mas também a conscientização. É esse diálogo dos professores e professoras, dos alunos e alunas sobre sua realidade, sobre as circunstâncias concretas que envolvem suas vidas, mediado por uma prática pedagógica livre e crítica, o responsável pela tomada de consciência dos alunos e alunas enquanto sujeito de direitos. 0 reconhecimento do processo histórico de vitimização que marcou a vida desses sujeitos opera no sentido da conquista da autonomia.

Somente a partir do diálogo sobre as circunstâncias concretas que afetam/ afetaram suas vidas, uma prática pedagógica em DH ganhará sentido. Porque as palavras, as experiências dizem respeito à vivência de ter sido excluído, desrespeitado, constrangido, violentado. Assim, a EDH trabalhará com o homem concreto, com o sujeito de direitos. Quando Freire em sua pedagogia como prática da liberdade opta pela educação do "homem simples, minimizado e sem consciência dessa minimização, [...] mais coisa que homem mesmo" (2011, p. 52), está optando por uma nova sociedade em que o homem e o povo fossem sujeitos de sua história.

Refletindo sobre o sujeito oprimido freireano e suas circunstâncias concretas, compreendemos que esse sujeito assumiu uma nova significação nas condições atuais de dominação. A luta agora é pelo sujeito consciente de seus direitos e cumpridor de seus deveres. Nesse contexto, falamos de DH como formas de vida humana concreta, corporal, material, que a partir do olhar das vítimas revela a ambiguidade da universalidade que Ihes é atribuida, desmascarando sua utilização, quando empregados para legitimar o sistema.

A Educação em e para os Direitos Humanos, em sua singularidade, deve fundamentar-se pelos princípios críticos da emancipação, da educação para liberdade e autonomia, pelo diálogo. No respeito ao ser humano, como pessoa ou como sujeito de direitos em suas circunstâncias concretas, a EDH é enriquecida pelo pensamento educacional e pela prática de uma educação como prática da liberdade, por uma pedagogia produtora de indivíduos conscientes das condições sociais e de autoprodução em que vivem. Os conhecimentos da EDH, alicerçados pelos saberes e práticas pedagógicas críticas, podem contribuir para a construção do sujeito de direitos, sujeito crítico e consciente de seu lugar no mundo.

A EDH deve ser ensinada e apreendida em seu aspecto multidimensional, tal como é, por exemplo, apresentada pelo Plano Nacional de Educação em Direitos Humanos - PNEDH, do Brasil: "Um processo sistemático e multidimensional que orienta a formação dos sujeitos de direitos," [...]. (BRASIL, 2006, p. 17). 
Na compreensão de Silva (2010, p. 49), o currículo básico da EDH, por exemplo, deve utilizar-se de conhecimentos que formam a área, como "história, os processos de evolução das conquistas e das violações dos direitos, as legislações, pactos e acordos que dão sustentabilidade e garantia aos direitos [...]", tomando a contextualização como conteúdo imprescindível e a cidadania como possibilidade para a ação.

Além de outras orientações, o mesmo documento aponta os principios que norteiam a EDH e que podem ser assim resumidos: a escola é o espaço por excelência para a efetivação dos $\mathrm{DH}$, devendo assegurar a perfeita correspondência entre objetivos e práticas e os valores e princípios da EDH. Pelo seu caráter coletivo, a EDH deve realizar-se em espaços marcados pelo entendimento mútuo, pelo respeito e pela responsabilidade, devendo estruturar-se na diversidade cultural e ambiental, garantindo a cidadania, o acesso ao ensino, a permanência, a equidade e a qualidade da educação. A EDH deve permear o currículo, a formação inicial e continuada dos profissionais da educação, o projeto político-pedagógico da escola, os materiais didático-pedagógicos, o modelo de gestão e a avaliação, orientando e perpassando a educação básica e as práticas que nela se realizam. (BRASIL, 2006).

A dimensão crítica da EDH exige formação pedagógica desses profissionais que deve ser orientada por fundamentos teórico-metodológicos críticos, tendo em vista que alunos e alunas possam tornar-se profissionais críticos, comprometidos com os DH. Na verdade, a preocupação é bem maior com o domínio de conteúdos, técnicas e disciplina.

Nessa perspectiva não existe interesse pelas experiências e histórias de vida dos alunos e alunas, sua relação com o processo de ensino e aprendizagem. No entanto, essas experiências deveriam ser tomadas como objeto de debate, legitimando-se, na medida em que são representativas da vida social.

0 trabalho do educador exige esse conhecimento, faz parte de sua postura ética, política e social. A abertura ao outro, aos seus saberes e práticas sociais enriquece as alternativas de problematização do conhecimento, pela utilização de um diálogo que diga respeito a questões concretas, vitais. Nesse contexto, o papel do professor é fundamental, trabalhando teoria e prática de modo integrado, para que o conhecimento torne-se crítico e emancipatório. Ora, se as necessidades podem ser construídas, podem também ser desfeitas e reconstruídas de acordo com as preocupações do sujeito que se quer emancipar.

Os professores podem contribuir com suas habilidades para o desenvolvimento de formas vitais de engajamento nos esforços da população contra a discriminação social, racial de gênero (o político se torna pedagógico, e o pedagógico, político). Ao aplicar os princípios críticos aos DH, é possível desenvolver uma prática pedagógica 
emancipatória, uma prática que considere as experiências dolorosas dos alunos e alunas, abrindo-se possibilidades para intervenções e mudanças, como parte do processo de ensino e aprendizagem em Direitos Humanos.

Vale então buscar alternativas democráticas, e uma Educação Crítica em Direitos Humanos constitui-se uma dessas alternativas, um espaço de luta pela dignidade humana.

A definição de Flores (2000, p. 4) sobre Direitos Humanos está em articulação com as novas perspectivas, quando afirma que são algo mais que declarações e pactos, os Direitos Humanos "são o conjunto de processos (normativos, institucionais e sociais) que abrem e consolidam espaços de luta pela dignidade humana". Essa definição orienta para a necessidade de compreender os Direitos Humanos a partir de seus contextos, de seus condicionamentos, de sua concretude. Porém, essa não é a concepção de DH veiculada formalmente. 0 que é passado é "um discurso descontextualizado, abstrato, a priori e universal, dentro de um âmbito formal". (ANDRADE, 2006, p. 274). Daí, a incerteza, o desgosto, o desconhecimento das pessoas ao tratarem os $\mathrm{DH}$, originando o questionamento: Para que servem? Por que a forma como são tratados não lhes diz nada, por que são tratados à margem da vida humana concreta? Não é suficiente apenas constarem nos textos constitucionais de quase todos os Estados do mundo, eles devem ser processos de luta pela vida. Desse modo, é tarefa de uma educação crítica em direitos humanos questionar e analisar os processos de fortalecimento da vida e da dignidade humana.

No âmbito da Pedagogia Crítica, do diálogo como princípio e categoria crítica para a EDH, professores e professoras devem dialogar com seus alunos e alunas sobre temáticas em $\mathrm{DH}$, que falem de suas experiências diárias em conformidade com suas condições concretas de existência. Nessa configuração, a prática pedagógica da EDH, tomando o diálogo como referência, estará valorizando as vozes, os saberes e as experiências em DH dos educandos, fornecendo-lhes os instrumentos e as alternativas para compreenderem criticamente e validarem as histórias de suas vidas, saindo da condição de assujeitados para sujeito de direitos.

Os princípios que alicerçam a teoria e a pedagogia críticas, anteriormente expostas, revalidam-se para a teoria e a prática em $\mathrm{DH}$, ou seja, a decodificação da realidade vivida, da situação de desrespeito à dignidade, a problematização pelo diálogo crítico, atualizam-se para o trabalho em EDH, para que então seja colocada a possibilidade de compreensão das relações sociais e educacionais de poder e opressão em que o educando/educador está inserido. A prática pedagógica crítica em DH implica um trabalho de interpretação e análise das palavras, cenários, vozes, imagens que marcaram a experiência vivida, para que a apropriação /decodificação de seu significado possa contribuir para a construção do sujeito de direitos. Conhecendo as causas do assujeitamento, a partir de uma leitura crítica da realidade e da discussão das experiências em $\mathrm{DH}$, os educandos terão possibilidades de entender por que em 
determinado momento de suas vidas sofreram apequenamento ou expropriação de seus direitos, abrindo-se espaço para a reflexão crítica e para a ação.

Professores e professoras que compreendem a EDH a partir de uma perspectiva crítica proporcionam em suas salas de aula um clima especial de ensino e aprendizagem para realização de seu propósito maior: em ponderar as pessoas para que sejam sujeitos de direito, emancipando-as pela consciência critica e pelo diálogo.

Uma EDH crítica deve refletir-se nos currículos, conhecimentos, valores, práticas e metodologias, transpondo visões e perspectivas acríticas e ingênuas, intervindo nas formas de ensinar e aprender, nas temáticas propostas, nos saberes e nas atividades desenvolvidas.

Em uma era ambígua e complexa como a que vivemos, que dificulta tanto sua nomeação como sua compreensão, em que são visiveis as condições de abandono, de sofrimento e de desprezo pela vida humana, é necessário que os professores e as professoras participem de um processo de reflexão crítica e desenvolvam novas perspectivas e práticas pedagógicas que contribuam para a compreensão e desvelamento das relações sociais e individuais, em sua complexidade e inter-relacionamento.

0 espaço educacional para o desenvolvimento da EDH configura-se, por isso, como dialógico, solidário, em que a mediação realiza-se em clima de igualdade sem imposição ou autoritarismo, visando à formação independente do aluno que deverá ter o domínio de sua própria aprendizagem.

Para que essa perspectiva se realize, a EDH utiliza estratégias de ensinoaprendizagem, ou no dizer de Magendzo (2012), adota distintas iniciativas no ensino, que, somadas a processos educativos de problematização das violências sofridas em DH pelos alunos na vida cotidiana, orienta para a análise das temáticas no contexto de relações, aprofundando a prática de participação democrática, de liberdade individual e coletiva, de justiça e de melhoria das condições sociais de vida.

0 trabalho crítico com DH será participativo, intelectualmente crítico, mobilizado para a transformação política e cultural, por meio de práticas sociais dentro e fora da escola e que são tecidas por um processo dialógico. Dai ser necessário que professores e professoras tenham presentes uma consciência clara das condições de possibilidade de uma educação emancipatória (Giroux, 1994), participando da análise crítica das experiências de vida de seus alunos.

Nesse sentido, vejamos as considerações de Estêvão (2012, p. 103) sobre a EDH:

A EDH, tal como a pedagogia crítica, deve privilegiar particularmente o diálogo com os sem-voz e os da periferia, os marginalizados e os excluídos; deve estar ligada, ainda, pelo 
pulsar da memória, à história das lutas de libertação do planeta e vincular-se à 'luta para ocupar um espaço de esperança'.

0 autor ainda afirma o caráter ético e político da EDH, pelo trabalho crítico de prevenção que realiza, sendo necessário que alunos e alunas aprendam e fortaleçam habilidades para o enfrentamento das questões/ações atuais de desrespeito aos DH.

Produzida em outro contexto, mas que se aplica perfeitamente ao momento presente de violência aos $\mathrm{DH}$, trazemos para o debate e para a prática crítica em DH a visão de Freire (2011) sobre educação como prática da liberdade, presente nas palavras de Estêvão (2012). "A educação é um ato de amor e, por isso, um ato de coragem. Não pode temer o debate. A análise da realidade. Não pode fugir à discussão criadora, sob pena de ser uma farsa" (FREIRE, 2011, p. 61). Nas palavras dos dois autores identificamos o conteúdo ético e político da Pedagogia Crítica e da EDH.

Vinculando-se à Pedagogia Crítica, e compreendida como possibilidade, a EDH deve promover o diálogo, a análise da realidade e seu enfrentamento. Nesse sentido, Estêvão $(2012$, p. 104) apresenta tarefas urgentes da EDH, considerada em uma perspectiva crítica:

[...] investir no aprofundamento de uma teoria emancipatória (ou seja, construir uma ciência da sociedade baseada numa consciência justa); articular-se com uma concepção de democracia mais radical, entendida como direitos humanos, construída sobretudo a partir da sociedade civil e tendo em devida conta a importância estratégica do espaço público e da sociedade civil; construir redes contra-hegemônicas que lutem contra a dominação e a opressão; mobilizar a justiça na sua tridimensionalidade (redistribuição, reconhecimento e participação); compreender a interdependência e a solidariedade mundiais, assim como as contradições que impedem a cooperação internacional e o desenvolvimento da paz; finalmente, recuperar a dimensão ético-politica da educação, contra o autoritarismo e a tecnocracia, a eficacia sem deliberação, a instrumentalidade gerencialista.

As tarefas mencionadas fazem parte do horizonte de possibilidades que a EDH, sob a orientação da Pedagogia Crítica, pode desenvolver. Porém, todas elas precisam estar articuladas com as circunstâncias concretas para ganharem sentido. Se falarmos, por exemplo, a um adulto da EJA, de uma escola periférica de João Pessoa, com uma história de vida marcada pelo desemprego, pela dor e pela fome, sobre a importância de ser um sujeito de direitos, sem relacionar a suas condições de sujeito vitimado pela exclusão, não haverá diálogo. Por outro lado, se apresentarmos situações com as quais se identifica, ele vai 
reconhecer-se no decorrer do diálogo, fazendo sentido para a EDH, as palavras de Weffort (2011, p. 14) sobre a pedagogia crítica freireana: "E assim a visão educacional não pode deixar de ser ao mesmo tempo uma crítica da opressão real em que vivem os homens e uma expressão de sua luta por libertar-se", cambiando o processo de conscientização para uma posição de luta. Nessa configuração, a pedagogia crítica fundamentará a EDH nas dimensões prática, política e social, orientando-a para a possibilidade de ser uma "educação para a decisão, para a responsabilidade social e política" (Freire, 2011), sugerindo novos horizontes.

\section{Considerações Finais}

A partir das discussões realizadas nesse trabalho, compreendemos que existem interfaces, intersecções entre a Pedagogia Crítica e a EDH que precisam ser consideradas e analisadas. A partir dessas articulações, vislumbramos a possibilidade de trabalhar a EDH, considerando princípios, saberes e práticas da Pedagogia Crítica, relevantes para a construção do sujeito de direitos.

Essa construção é possivel pela ação de educadores e educadoras que acreditam e trabalham por uma sociedade em que exista justiça para todos, igualdade na diversidade, respeito à própria dignidade e à dignidade do outro, e liberdade, tendo consciência da mutabilidade desses conceitos pela sua própria historicidade e da carga ideológica que os constitui.

Os conhecimentos formadores da EDH são saberes instrumentais tanto para a formação do sujeito de direitos como para sua ação e intervenção na sociedade. Conhecendo os próprios direitos e os dos outros, e a possibilidade de agir frente às injustiças, o sujeito empoderado pelos saberes de uma EDH poderá participar da defesa e da promoção dos direitos humanos.

A EDH, a partir de uma perspectiva crítica, poderá assumir a configuração de uma educação ética e política, preocupando-se com problemas que afligem a sociedade. Na verdade, a EDH já se preocupa com tais problemas. No entanto, existe uma lacuna, no que diz respeito às formas de enfrentamento, de escolha de um caminho político que permita sonhar com democracia e com justiça. Daí, a necessidade de professores e professoras procurarem desenvolver habilidades com seus alunos e alunas que orientem para a participação, para a análise crítica e para o enfrentamento desses problemas. Os fundamentos da teoria e da Pedagogia Crítica em consonância com os objetivos da EDH terão um importante papel no desenvolvimento do trabalho pedagógico.

Nessa perspectiva, uma pedagogia crítica para a Educação em Direitos Humanos pode contribuir para o trabalho pedagógico na medida em que compreende e 
discute as novas formas de desenvolvimento, repensa as propostas educacionais e de ação político-pedagógica para controlar/subverter seus efeitos, desconstrói o debate educacional/social estabelecido sobre $\mathrm{DH}$, articulando estratégias, políticas e práticas pedagógicas de respeito e solidariedade.

Sabemos, com fundamento em nossa prática pedagógica no ensino superior e em projetos de intervenção/extensão em $\mathrm{DH}$, das dificuldades enfrentadas para adoção pelo sistema educacional de uma prática educativa em DH e da incorporação de uma visão crítica. Contudo, há necessidade de educadores e educadoras se formarem, e buscarem novas alternativas e/ou estratégias educacionais que contribuirão para o empoderamento dos educandos e possivel ação ou enfrentamento das injustiças enquanto indivíduos ou coletividade.

Consideramos, para tanto, a importância da sensibilização de professores e professoras, alunos e alunas para o trabalho com as temáticas em $\mathrm{DH}$, conhecendo-as, analisando-as em sua complexidade conceitual e histórica. Nesse sentido, o que esperamos dos professores e professoras, o que esperamos "de quem ensina, falando ou escrevendo, em última análise, testemunhando, é que seja rigorosamente coerente, que não se perca na distância enorme entre o que faz e o que diz". (FREIRE, 1994, p. 17). Essa é uma obrigação e uma exigência ética que diz respeito também ao outro, ao aluno, àquele que espera ética e coerência na prática professoral, àquele que toma como verdade a palavra do professor, revelando-se nesse aspecto a corresponsabilidade das palavras e também das ações do professor. Aqui, encontram eco os ensinamentos freireanos sobre uma educação da verdade, mas também da utopia, da esperança, da imaginação criativa e da tolerância, em que ação política e pedagógica se unem numa dialética de unidade na diversidade, sendo possivel sonhar com justiça social.

Nesse sentido, podemos falar de uma prática educativa crítica em DH como forma de contribuição para o desenvolvimento da vida humana, de uma vida humana digna, como forma também de conhecimento e participação da realidade do excluído e diminuição do seu sofrimento. Porque mais de quarenta anos depois da criação de uma pedagogia radical para os pobres do mundo, considerados por Freire como seres humanos, esses oprimidos e oprimidas "não fazem sinão aumentar em número, e ainda assim se fizeram todavia mais invisiveis, em certo modo. Lutam contra a domesticação da colonização que subjaz em termos como globalização e desvantagens". (GRANDE, 2008, p. 431). É nessa conformação que Pedagogia Crítica e Educação em Direitos Humanos se encontram, se confrontam e se complementam, surgindo a esperança como desafio e como crença de que ainda é possivel melhorar o ser humano e sua convivência no mundo. 


\section{Referências}

ANDRADE, P. V. Teoría crítica de la educación: lineamentos para una propuesta educativa. León: Universidad de León; Secretariado de Publicaciones, 2006.

APPLE, M. W. Conclusão. In: APPLE, M. W.; NÓVOA, A. (Org.). Paulo Freire: política e pedagogia. Porto, PT: Porto Editora, 1998.

BERRY, K. S. Lugares (o no) de la pedagogía crítica en les petites et les grandes histoires. In: MCLAREN, P.; KINCHELOE, J. L. (Org.). Pedagogía crítica: de qué hablamos, dónde estamos. Barcelona: GRAÓ, 2008. p. 116-140.

BOBBIO, N. A era dos direitos. Tradução de Carlos Nelson Coutinho. Rio de Janeiro: Elsevier, 2004.

BRASIL. Comitê Nacional de Educação em Direitos Humanos. CNEDH. Ministério da Educação. Plano Nacional de Educação em Direitos Humanos. Brasilia, DF: Secretaria Especial dos Direitos Humanos da Presidência da República; MEC; MJ/UNESCO, 2006.

FLORES, J. H. (Org.). El vuelo de Anteo: derechos humanos y crítica de la razón liberal. Bilbao: Editorial Desclée de Brouwer, 2000.

FREIRE, P. Política e educação. São Paulo: Cortez, 1993.

. Cartas a Cristina. Rio de Janeiro: Paz e Terra, 1994.

Pedagogia da autonomia: saberes necessários à prática educativa. São Paulo: Paz e Terra, 2002.

Pedagogia da indignação: cartas pedagógicas e outros escritos. São Paulo; Editora UNESP, 2000.

. A pedagogia da esperança: reencontro com a pedagogia do oprimido. Rio de Janeiro: Paz e Terra, 2004.

. Educação como prática da liberdade. 14. ed. rev. atual. Rio de janeiro: Paz e Terra, 2011.

GIROUX, H. Pedagogia radical: subsídios. Tradução de Dagmar M. L. Zibas. São Paulo: Cortez; Autores associados, 1983. . Disturbing pleasures. Learning popular culture. London: Routledge, 1994. 
Introducción: democracia, educación y política en la pedagogía crítica. In: MCLAREN, P.; KINCHELOE, J. L. (Org.). Pedagogía critica: de qué hablamos, dónde estamos. Barcelona: GRAÓ, 2008. p. 17-22.

GRANDE, S. Red lake desconsolado: pedagogia, descolonização e o projeto crítico. In: MCLAREN, P.; KINCHELOE, J. L. (Org.). Pedagogía crítica: de qué hablamos, dónde estamos. Barcelona: GRAÓ, 2008. p. 431-459.

HUERTA-CHARLES, L. Pedagogía del testimonio: reflexiones sobre la pedagogía crítica. In: MCLAREN, P.; KINCHELOE, J. L. (Org.). Pedagogía crítica: de qué hablamos, dónde estamos. Barcelona: GRAÓ, 2008. p. 305-355.

KINCHELOE, J. L. La pedagogía crítica en el siglo XXI: evolucionar para sobrevivir. In: MCLAREN, P.; KINCHELOE, J. L. (Org.). Pedagogía crítica: de qué hablamos, dónde estamos. Barcelona: GRAÓ, 2008. p. 25-69.

LEISTYNA, P. Sinsentidos neoliberales. In: MCLAREN, P.; KINCHELOE, J. L. (Org.). Pedagogía crítica: de qué hablamos, dónde estamos. Barcelona: GRAÓ, 2008. p. 141-200.

MAGENDZO, K. A. Educación en derechos humanos: un desafío para los docentes de hoy. Santiago: LOM Ediciones, 2012. Disponivel em: <http:// biblioteca.ucn.edu.co/repositorio/Especializaciones/Esp.GerenciaEducativa/ CorrientesProblemasPedagogicos/documentos/PEDAG0GIA\%20CRITICA\%20\%20 MAGENTZO.pdf. >. Acesso em: 12 ago. 2012.

MCLAREN, P. El futuro del pasado: reflexiones sobre el estado actual del imperio y de la pedagogía. In: MCLAREN, P.; KINCHELOE, J. L. (Org.). Pedagogía critica: de qué hablamos, dónde estamos. Barcelona: GRAÓ, 2008.p. 393-429.

MEINTJES, G. Educação em direitos humanos para o pleno exercício da cidadania: Repercussões na pedagogia. In: ANDREOPOULOS, G. J.; CLAUDE, R. P. (Org..). Educação em Direitos Humanos para o século XXI. São Paulo: EDUSP: Núcleo de Estudos da Violência, 2007. p. 119-140.

SILVA, A. M. M.; TAVARES, C. (Org.). Políticas e fundamentos da educação em direitos humanos. São Paulo: Cortez, 2010.

SILVA, A. J. A. Henry Giroux: A pedagogia como possibilidade crítica. 1999. Dissertação-(Mestrado). Programa de Pós-Graduação em Filosofia da Educação, Instituto de Educação, Universidade do Minho, 1999, Braga, PT. 
TORRES, C. A. Teoria crítica e sociologia política da educação. In: TORRES, C. A. (Org.). Teoria crítica e sociologia política da educação. São Paulo: Cortez: Instituto Paulo Freire, 2003.

WEFFORT, F. C. Educação e política: reflexões sociológicas sobre uma pedagogiada liberdade. In: FREIRE, P. Educação como prática da liberdade. 14. ed. rev. atual. Rio de Janeiro: Paz e Terra, 2011. p.7-39.

Recebido em: 27/05/2013

Aceito para publicação em: 01/08/2013

\section{Critical pedagogy and Human Rights: fundamentals for a critical-pedagogical proposal in Human Rights Abstract}

This article reflects about the necessity of find a pedagogical theory that offers lift to educational action in Human Rights, showing a critical-pedagogical proposal based in the assumptions of the theory and of the critical pedagogy, privileging the freireana pedagoy in the update perspective for Human Rights. So, the work proposes to discuss a theorical-critical fundament for the Education in Human Rights, looking for new investigation forms and for analysis to its comprehention, getting critical concepts like awareness, autonomy, dialogue and emancipating. Finally, considers that a critical pedagogical practices in Human Rights contributes to the reading of the deleted people world, to their inclusion in the society and to the comprehention of the possibility of deconstructing unfair social practices and relationships.

Keywords: Critical theory. Freireana Pedagogy. Pedagogical proposal in Human Rights. Critical fundaments.

\section{Pedagogía crítica y derechos humanos: fundamentos para una propuesta crítico- pedagógica en derechos humanos}

\section{Resumen}

Este artículo analiza la necesidad de buscar una teoría pedagógica que ofrezca sustentación a la acción educativa en Derechos Humanos, presentando una propuesta pedagógico-crítica, basada en los presupuestos de la teoría y de la pedagogía críticas, privilegiando la pedagogía freireana en una perspectiva actualizada para los Derechos Humanos. Así, el trabajo tiene el propósito de discutir un fundamento teórico-crítico para la Educación en Derechos Humanos, buscando nuevas formas de investigación y de análisis para su comprensión, apropiándose de conceptos críticos 
como concienciación, autonomía, diálogo y emancipación. Finalmente, considera que una práctica pedagógica crítica en Derechos Humanos contribuye para la lectura del mundo del excluido, para su inclusión en la sociedad y la comprensión de que es posible desconstruir relaciones y prácticas sociales injustas.

Palabras clave: Teoría crítica. Pedagogía freireana. Propuesta pedagógica en Derechos Humanos. Fundamentos críticos. 